\title{
Barriers to knowledge management in small and medium construction companies in South Africa
}

\author{
Douglas Aghimien $^{\mathrm{a} *}$, Clinton Aigbavboa ${ }^{\mathrm{a}}$, Fernando Gomes, Wellington Thwala ${ }^{\mathrm{a}}$ \\ ${ }^{a}$ SARChi in Sustainable Construction Management and Leadership in the Built Environment, Faculty of Engineering and the Built Environment, \\ University of Johannesburg
}

\begin{abstract}
Small and medium enterprises (SMEs) within the construction industry have been described to be falling short in the adoption of several management practices that could help improve their service delivery and subsequent growth within the industry. Thus, this study set out to determine the various factors that could serve as barriers towards achieving proper knowledge management (KM) within these construction organisations. The study adopted a quantitative approach through the use of a questionnaire survey carried out among staff members and stakeholders in management positions of Grade 1 to 3 general building organisations within the Johannesburg region of South Africa. Data gathered were analysed using percentage and factor analysis. The reliability of the research instrument was also tested using Cronbach alpha test while the factorability of the data gathered was tested using the Kaiser-Meyer-Olkin measure of sampling adequacy and Bartlett's Test of Sphericity. The result revealed that the barriers to proper KM practices among SMEs in the study area can be categorised under the following: people related issues, SMEs organisational issues, and project demand issues. It is believed that the findings of this study will go a long way in assisting SME's owners in managing knowledge within their organisation by avoiding certain factors that could hinder effective KM.
\end{abstract}

(C) 2019 The Authors. Published by Budapest University of Technology and Economics \& Diamond Congress Ltd.

Peer-review under responsibility of the scientific committee of the Creative Construction Conference 2019.

Keywords: Barriers; Knowledge management; Organisation management; Project management; Small and medium companies.

\section{Introduction}

The construction industry is a dynamic sector of ever-changing design developments posed by various design teams. It has been observed that companies put greater emphasis on constructing the final product than focusing on planning the contract program [1]. In doing this, project participants are appointed based on their expertise and background knowledge on the current work to be undertaken [2]. Despite this, most projects experience setbacks due to ineffective planning during their early stage [3]. A major set of construction companies faced with this challenge are the small and medium enterprises (SMEs). Although these construction companies have been described as the key drivers of economic growth [4], their activities and productivity are laden with problems such as poor project planning and ineffective management [5]. A crucial aspect is that of proper management of knowledge acquired within the organisation.

Most SME's are operated by owners who hardly have good background knowledge in the industry. These owners in most cases hope that their employees (experienced or not) will fill in this knowledge gap [6]. Unfortunately, it has been noted that stakeholders of the construction industry find it hard to share knowledge within an organisation. World 
Aghimien et al., / Proceedings of the Creative Construction Conference (2019) 031

https://doi.org/10.3311/CCC2019-031

Economic Forum [1] observed that institutional memory is not being conveyed equally between the stakeholders of the construction industry. Engineers and other construction experts have become organisation's asset with the domain knowledge, and unfortunately, they tend to leave little or no knowledge at all behind for future projects when they eventually exit the organisation [7]. Civi [8] noted that stakeholders of any organisation are the originators and developers of knowledge through which a cumulative bank of knowledge that over time creates the process of the entire organisation is achieved. Therefore, organisations need to find a way in which they can manage this knowledge. According to Nakamori [9], through prehistoric knowledge, stakeholders of a company (SMEs inclusive) can solve challenges they are faced with at any particular time and can be creative to innovate and develop new ideas. Linde [10] therefore suggested that empowering stakeholders with what they need to know and allowing them a fair opportunity to express their opinions which is usually based on experience allows for the transfer of knowledge. Thus, it is not gainsaying that proper knowledge management $(\mathrm{KM})$ is crucial for the growth and survival of SMEs within the construction industry considering the competitive nature of the industry. Robinson et al. [11] have earlier noted that KM helps create an enabling environment for the creation, storage and transfer of knowledge within an organisation.

Based on the above, this study assessed the barriers of KM in small and medium construction companies in South Africa with a view towards increasing the adoption of KM practices within SMEs in the construction industry and by extension improves their service delivery. Subsequent parts of this paper present the review of related literature, the methodology adopted for the study, the findings and conclusion. Based on the conclusion, recommendations were given.

\section{Literature Review}

Organisations in various sectors operate based on the knowledge individuals have gained over years of experiences in a particular field [12]. Knowledge is a resource in its self, which defines the modes and routes an organisation applies to its operational processes [8]. KM helps organisations in creating a working space where knowledge can be created, stored and transferred within the organisation [11]. Linde [8] stated that knowledge comes in two forms which are explicit and tacit knowledge. The explicit knowledge is widely accessible through the means of books and media, while the tacit knowledge is not visible and precise, thus, making it difficult to create, organise and transfer it to someone else. However, the latter is the type of knowledge that plays a major role in having the competitive advantage against other organisations through which organisations are able to tackle any challenge they are faced with [7, 13].

It has been established that organisations in developing countries are not as efficient as those countries in the developed countries. Due to tense socio-economic factors, stakeholders from both formal and informal organisations have a tendency to unconsciously reducing their productiveness [14]. Hence it is important to work within the current culture of an organisation as they are enduring the impact of cultural diversity. Organisations should rather change the behaviours of the stakeholders to improve current flaws within the organisation [15]. As the organisation improves its flaws and knowledge is being transferred between stakeholders, the entire organisation begins to improve its performance [16]. Constant sharing of knowledge will ensure that the organisation propels its self to improve on its errors, which will reduce costs and save time. It is important that an organisation understands and values knowing precisely what the clients want for their projects. The organisation may be motivated to come up with new management techniques, processes and convenient work methods which will promote growth and expansion for the organisation and meet the client's needs [17].

Despite the advantage proposed by proper KM within organisations, most construction organisations are still falling short in the proper management of knowledge and this is evident in their service delivery. Some peculiar factors seem to be affecting the adoption of proper KM practices among construction organisations, particularly with SMEs. Herrington et al. [18] reported that most SME's do not have a good financial history and are unable to create a viable business plan which make it difficult for them acquire funding from financial institutions. It gets even more difficult for SME's to ascertain funding as the interest rate is continuously increasing making it even more difficult for them to survive the competitive environment. The implementation of advanced KM practices tends to be costly for most small and medium construction organisations as they need to start out from basic KM systems and gradually recycle these 
Aghimien et al., / Proceedings of the Creative Construction Conference (2019) 031

https://doi.org/10.3311/CCC2019-031

into advanced systems which help organisations to reach their full potential [19, 20, 21]. It has also been observed that most SME's cannot afford to hire professional stakeholders. This has resulted to them hiring family members who do not have the adequate knowledge and skills of the construction industry [22]. The CIDB [12] further affirmed this by stating that most owners of small and medium construction organisations run it themselves and have vague construction knowledge. This makes it even harder for them to understand the principles of running such an organisation.

Budget constraints reduce the capabilities of an organisation to invest their money in keeping their employees upskilled and in the know of currently existing knowledge in the market. Depending on the owner's willingness to share knowledge and keep the employees motivated, budget constraints may limit the promotions, rewarding structures which could have kept employees motivated, leading them to a reluctant approach in sharing knowledge [23]. There is a vast amount of literature that proves that stakeholders have limited time to share knowledge within organisations. Although they may be willing to share knowledge, they are often under pressure as projects have time constraints which do not allow for such cultures activities to occur [21,24,25]. This limits the absorption and growth of both the individual and the organisation. This lack of time to share knowledge also impedes organisation's ability to audit and debrief the current knowledge the organisation has attained during a project's lifecycle [25]. It has earlier been suggested that adequate time should be created so that management within an organisation can constantly check on the knowledge they have acquired. Through this, they can also decide on what best suits the core objectives of the organisation and if it requires advancement they can decide on what practices to employ to achieve this $[16,22]$.

\section{Research Methodology}

In assessing the barriers of KM in small and medium construction companies in South Africa a survey approach was adopted. The survey was conducted within the greater Johannesburg region, targeting relevant stakeholders who worked for SMEs with a CIDB grading between 1 and 3 in General Building. Management and staff members of SMEs within the study area were sampled based on their willingness to participate in the survey and by the virtue of their construction experience. The greater Johannesburg region was selected as the study area due to the high concentration of construction organisations within the area and the availability of construction projects within the city and surrounding regions. A structured questionnaire based on findings from the review of literature was adopted as the instrument for data collection. The choice of a questionnaire survey is premised on the fact that the questionnaire has been adjudged to be easiest and most widely used research instrument in most social researches and it has the ability to cover a wide range of respondents [26, 27]. A total of 80 questionnaires were conveniently distributed with 53 retrieved and found fit for data analysis. The questionnaire used was designed in sections with the first section geared towards gathering information on the respondent's background. The second section sort answers regarding the barriers of KM in small and medium construction companies in South Africa. Respondents were provided with a list of barriers identified from literature to rate based on their level of significance. A Likert scale of 1 to 5 was employed, with 5 being very high, 4 being high, 3 being average, 2 being low and 1 being very low. Data analyses were done using percentage for data on the background information of the respondents. Factor Analysis was conducted on the data gathered on the barriers of KM in small and medium construction companies. The reliability of the questions in this second section was tested using Cronbach's alpha test which gave an alpha value of 0.915 , thus implying high reliability of the questionnaire used.

\section{Results and Discussion}

\subsection{Background information}

The result on the background information of the respondents revealed that $2 \%$ of the respondents had no formal qualification, $9 \%$ had a Grade 9 qualification, $28 \%$ had a Grade 12,38\% had a diploma, and 23\% had a bachelor's degree. Out of these qualifications, the result further revealed that only $65 \%$ were related to construction, with $35 \%$ not related. In terms of their position within the organisation, the result revealed that $21 \%$ of the respondents were the owners, $4 \%$ were quantity surveyors within the SMEs, $30 \%$ were construction managers, and $45 \%$ were the 
Aghimien et al., / Proceedings of the Creative Construction Conference (2019) 031

https://doi.org/10.3311/CCC2019-031

foremen/supervisors. The respondents' years of experience within the construction sector was also assessed and result revealed that $17 \%$ of respondents have between 1 to 3 years of experience, $30 \%$ have 4 to 6 years, $25 \%$ have 7 to 10 years, and $28 \%$ have 11 or more experience in the construction industry. Most (43\%) of these respondents work in an organisation that is eligible to handle projects between R0 to R200,000, while $15 \%$ and $42 \%$ work within organisations that handle between R200, 000 to R650, 000 and R650,000 - R2million. Based on the result, it can be deduced that although the qualification level of workers within the assessed SMEs is somewhat low, their level of experience within the industry is high enough to give considerable answers to the research question base on experience.

\subsection{Barriers of KM in small and medium construction companies in South Africa}

In determining the barriers of KM in small and medium construction companies in South Africa, 13 key barriers were identified from the review of literature and presented to the respondents to rate according to their level of significance. Considering the fact that there is the likelihood of some of the identified barriers having similar underlying effects, factor analysis (FA) was deemed necessary to further group these barriers into a smaller number of coherent subscales. Although there have been several disparities as regards the ideal size of a sample for FA to be conducted, Preacher and MacCallum [28] suggested that as long as the communalities are high, and the expected number of factors is small, lesser consideration should be placed on sample size. Zhao [29] suggested communalities of 0.6 and above as being suitable irrespective of the sample size being adopted. The result from the communalities analysis revealed that all the assessed variables have communalities figure above 0.6. The result in Table 1 shows the Kaiser-Meyer-Olkin (KMO) measure of sampling adequacy and Bartlett's test of sphericity which were also used to ascertain the factorability of the data gathered. The result of the KMO test gave a value of 0.778 and a significant level of 0.000 for Bartlett's test which revealed that the use of FA for the data gathered is appropriate.

Table 1: Result of Kaiser-Meyer-Olkin and Bartlett's test

\begin{tabular}{llr}
\hline Kaiser-Meyer-Olkin Measure of Sampling Adequacy & & 0.827 \\
Bartlett's Test of Sphericity & Approx. Chi-Square & 495.881 \\
\cline { 2 - 3 } & df & 78 \\
\cline { 2 - 3 } & Sig. & 0.000 \\
\hline
\end{tabular}

Conducting FA using principal component analysis (PCA) with varimax rotation, 3 components with eigenvalues greater than 1 were extracted with 0.50 set as the cut-off point for the factor loading. The final statistics of the PCA and the components extracted accounted for approximately $75 \%$ of the total cumulative variance. A look at the scree plot in figure 1 further confirms this extraction as clear elbow can be seen from the third component above. The 3 extracted factors and their variables are shown in Table 2. 
Aghimien et al., / Proceedings of the Creative Construction Conference (2019) 031

https://doi.org/10.3311/CCC2019-031

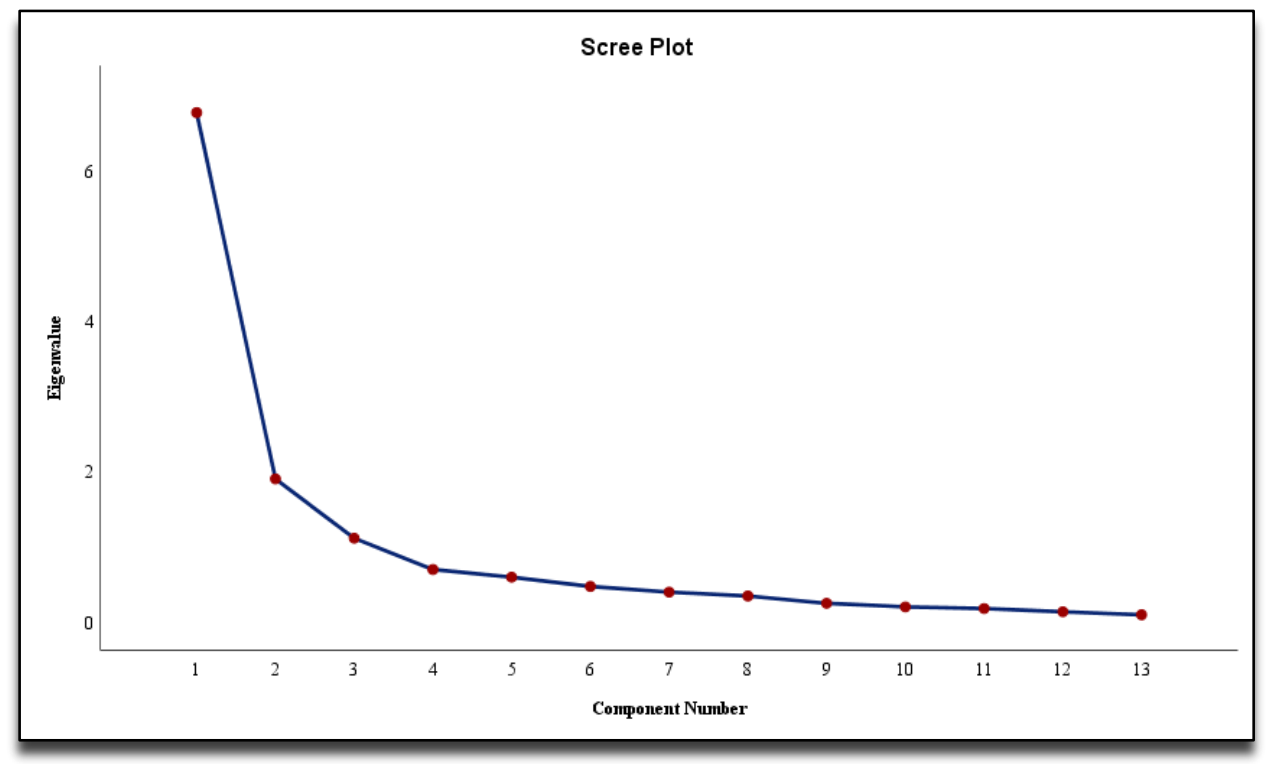

Figure 1: Scree plot

Table2: Rotated Component Matrix

\begin{tabular}{lcc}
\hline & \multicolumn{2}{c}{ Component } \\
\cline { 2 - 3 } Barriers & 1 & 2 \\
\hline Owner's/management's inability willingness to share knowledge & 0.808 \\
Owners lack construction knowledge & 0.791 \\
Unknowledgeable labour force & 0.758 & \\
Lack of research and innovation & 0.710 \\
Inability to implement educational/upskill training programs & 0.671 & \\
Inability to hire experts & & 0.870 \\
Lack of resources & 0.809 \\
Difficulty in getting funds & 0.731 \\
Expensive IT systems & 0.660 \\
Lack of projects strategic planning & & 0.591 \\
Limited time to share knowledge due to projects demands & & 0.897 \\
Lack of debriefing analysis & & 0.803 \\
Lack of rewards and recognition & & 0.707 \\
\hline
\end{tabular}

Extraction Method: Principal Component Analysis.

Rotation Method: Varimax with Kaiser Normalization.

\subsection{Discussion of Extracted Factors}

\section{a. People related issues}

The first principal component has a factor loading of 5 variables and it accounts for $52 \%$ of the total variance explained. This percentage is higher than the percentage for the remaining two extracted factors combined. This means that variables loading on this component are key barriers of KM in small and medium construction companies in the study area. These barriers are; owner's/management's inability willingness to share knowledge, owners lack construction knowledge, unknowledgeable labour force, lack of research and innovation, and inability to implement educational/upskill training programs. Based on the latent properties of these variables, this component was named the 
Aghimien et al., / Proceedings of the Creative Construction Conference (2019) 031

https://doi.org/10.3311/CCC2019-031

"People related issues". There is no gainsaying that being knowledgeable in construction activities is important so as to be able to impact such knowledge on others. This is important in knowledge transfer. At the same time, the willingness to transfer acquired knowledge is key if organisations are to improve in terms of their wealth of knowledge. However, the result has revealed that SMEs fall short in these areas and also in terms of upskill training programs for workers to attain the required knowledge. This result is in line with the submissions of Thwala and Mvubu [5] which noted that most SMEs in the construction industry is characterised with inadequate professional knowledge. In a similar vein, the problem of upskilling of employee's potentials and knowledge through training has been associated with poor financial standing and lack of budget allocated to same [23]. Therefore, if SMEs are to acquire, retain and transfer knowledge conveniently, factors relating to the people within the organisations and their attitude towards proper KM should be given considerable attention.

\section{b. SME's organisational issues}

The second principal component has a factor loading of 5 variables and it accounts for only $14.5 \%$ of the total variance explained. The variables loading on this component are; inability to hire experts, lack of resources, difficulty in getting funds, expensive IT systems, and lack of projects strategic planning. These variables all relate to shortcomings within SMEs itself. This is component is named "SME's organisational issues". Issues affecting SMEs are bound to limit their ability to adopt KM practices effectively. SMEs have been characterised with challenges such as lack of access to financial funding due to a prolonged recession which limits their leveraging capabilities and lack of access to markets [30]. This finance issue affects their ability to employ the right set of workers and also train the available one as observed by [22,23]. Thwala and Mvubu [5] have earlier noted that issues such as the absence of suitable application of scientific knowledge, poor management and business control, lack of practical scientific skills, and poor resource control. All these are issues emanating from the running of these small and medium organisations and they tend to affect the proper management of knowledge.

\section{c. Project demand issues}

The last extracted component account for only $8.5 \%$ of the total variance explained and has 3 variables loading on it. These variables include; limited time to share knowledge due to projects demands, lack of debriefing analysis, and lack of rewards and recognition. This component was subsequently named "project demand issues". Construction projects are time-consuming with construction participants having little or no time to prepare for new projects in most cases. This limited time tends to affect the transfer of knowledge from one project to another and even among project participants. While participants may have the true intention of sharing knowledge, they are in most cases constrained by time to achieve this. This finding is in line with the submissions of [24] and [25]. Therefore, if construction SMEs are to improve in their service delivery and gain better competitiveness through proper management of their knowledge, then more time need to be created in achieving this feat as suggested by [16] and [22].

\section{Conclusion}

The study assessed the barriers of KM in small and medium construction companies in South Africa through a quantitative approach with data gathered from staff members and stakeholders in management positions of Grade 1 to 3 General Building organisations within the Johannesburg region of South Africa. Based on the findings of the study, it is, therefore, concluded the key barriers of KM in SMEs are mostly people related issues, SMEs organisational issues, and project demand issues. If SMEs within the South African construction industry is to improve their service delivery through proper KM, there is the need to improve their human capital. Gaining proper construction knowledge through proper training of their labour force, and being willing to transfer this knowledge gained is imperative. Similarly, proper management of organisational issues such as hiring the right experts within the organisation, and having the right project strategic planning will help in the proper adoption of KM practices. Also, creating more time for knowledge transfer is necessary. Adequate debriefing after each project and proper planning towards new ones based on lessons learnt from previous projects is necessary. 
Aghimien et al., / Proceedings of the Creative Construction Conference (2019) 031

https://doi.org/10.3311/CCC2019-031

Although this study contributes to the body of knowledge by bringing to light of the key barriers of KM in small and medium construction companies, care must be taken in generalising the result of the study due to some identified limitations. The study was limited to a single province within the country, thus, there is a need for further studies in other provinces within the country, in order to compare results. There is also the need for further studies conducted with a much larger sample size than what is obtainable in this current study.

\section{References}

[1] World Economic Forum. Shaping the Future of Construction A Breakthrough in Mind set and Technology. Industry Agenda, 2006, 1-64

[2] K.Y. Mok, G.Q. Shen, R.J. Yang, C.Z. Li. Investigating key challenges in major public engineering projects by a network-theory based analysis of stakeholder concerns: A case study. International Journal of Project Management, 2017) 78-94. https://doi.org/10.1016/j.ijproman.2016.10.017

[3] W.D. Thwala, M.J. Phaladi. An exploratory study of problems facing small contractors in the North West province of South Africa. African Journal of Business Management, 3(2009) 533-539 https://doi.org/10.5897/AJBM09.122

[4] L. Wentzel, J.J. Smallwood, F.A. Emuze, F.A. Improving the Business Trajectory Among Small and Medium Size Construction Firms in South Africa. Journal of Construction Project Management and Innovation, 6(2016) 1477-1488

[5] W.D. Thwala, M.R. Mvubu. Problems Facing Small and Medium Size Contractors in Swaziland. Journal Service Science and Management, 2(2009) 353-361 http://dx.doi.org/10.4236/jssm.2009.24042

[6] B.M. Arthur-Aidoo, C.O. Aigbavboa, W.D. Thwala, W.D. Attitudes of owners which impedes firm's growth: A case of small and mediumsized construction firms in Ghana. Procedia engineering, 164 (2016) 231-233 https://doi.org/10.1016/j.proeng.2016.11.614

[7] F.L. Ribeiro. Knowledge Management in Construction Sites. Emirates Journal for Engineering Research, 13(2008) 2-10 https://doi.org/10.1080/15623599.2015.1012138

[8] E. Civi. Knowledge management as a competitive asset: A review. Marketing intelligence and planning, 18(2000) 166-169 https://doi.org/10.1108/02634500010333280

[9] Y. Nakamori. Systemic thinking in knowledge management. Managing knowledge for global and collaborative innovations, 2010, 399-411

[10] C. Linde. Narrative and social tacit knowledge. Journal of knowledge management, 5(2001) 162-166 https://doi.org/10.1142/7698

[11] H.S. Robinson, P.M. Carrillo, C.J. Anumba, A.M. Al-Ghassani. Knowledge management practices in large construction organisations. Engineering, construction and architectural management, 12(2005), 431 - 445 https://doi.org/10.1108/09699980510627135

[12] Construction industry development board (CIDB). Labour and Work Conditions in the South African Construction Industry, 2005, 1-8

[13] B. Gupta, L.S. Iyer, J.E. Aronson. Knowledge management: Practices and challenges. Industrial management and data systems, 100(2000) 17-21 https://doi.org/10.1108/02635570010273018

[14] K. Hutchings, K. Mohannak. Knowledge Management in Developing Economies: A Cross Cultural and Institutional Approach $1^{\text {st }}$ Edition, 2007, Edward Elgar Publishing, UK. https://doi.org/10.1108/02635570010273018

[15] J. Katzenbach, C. Oelschlegel, J. Thomas. J. 10 Principles of Organisational culture. strategy + business, 2016. Available from: https://www.strategy-business.com/article/10-Principles-of-Organizational-Culture?gko=71d2f

[16] F.L. Ribeiro. Enhancing knowledge management in construction firms. Construction innovation, 9(2009) 270-273 https://doi.org/10.1108/14714170910973493

[17] W. Baker, J. Sinkula. The synergistic effect of market orientation and learning orientation on organizational performance. Journal of the academy of marketing science, 27(1999) $413-416$

[18] M. Herrington, P. Kew, A. Mwanga. South Africa Report 2016/2017 Can Small Businesses Survive in South Africa? 2017. Available from: http://www.gemconsortium.org/country-profile/108

[19] J.C.N. Wee, A.Y.K. Chua. The peculiarities of knowledge management processes in SMEs. Journal of knowledge management, 17(2013), 958-972 https://doi.org/10.1108/JKM-04-2013-0163

[20] C.S. Lee, K.Y. Wong. Development and validation of knowledge management performance measurement constructs for small and medium enterprises, Journal of Knowledge Management, 19 (2015) 711-734 http://dx.doi.org/10.1108/JKM-10-2014-0398

[21] N. Chileshe, R. Rameezdeen, R.M. Hosseini, S. Lehmann. Barriers to implementing reverse logistics in South Australian construction organisations. Supply Chain Management: An International Journal, 20(2015) 179-204 https://doi.org/10.1108/SCM-10-2014-0325

[22] Y.K. Wong. Critical success factors for implementing knowledge management in small and medium enterprises. Industrial management and data systems, 105(2005) 261-279 https://doi.org/10.1108/02635570510590101

[23] E.C. Wenger, W.M. Snyder, W.M. Communities of practice: The organizational frontier. Harvard Business Review, $78(2006), 139$ - 145

[24] M. Shokri-Ghasabeh, N. Chileshe. Knowledge management: Barriers to capturing lessons learned from Australian construction contractor's perspective, Construction Innovation, 14 (2014) 108-134 https://doi.org/10.1108/CI-06-2013-0026

[25] M. Wendling, M. Oliveira, A.C.G Maçada. Knowledge sharing barriers in global teams. Journal of Systems and Information Technology, 15 (2013) 239-253 https://doi.org/10.1108/JSIT-09-2012-0054

[26] L. Blaxter, C. Huges, M. Tight. How to Research, 2nd ed., 2001, Open University Press, London

[27] W.C.K. Tan. Practical Research Methods, 2011, Pearson Custom: Singapore

[28] K.J. Preacher, R.C. MacCallum. Exploratory Factor Analysis in Behaviour Genetics Research: Factor Recovery with Small Sample Sizes, Behaviour Genetics, 32, 2002, 153-161

[29] Zhao, N., (2008). The Minimum Sample Size in Factor Analysis, 2008. Available on: https://www.encorewiki.org/plugins/servlet/mobile\#content/view/25657

[30] C.O. Aigbavboa, W.D. Thwala, W.D. Challenges facing black owned small and medium construction companies. Journal of economics and behavioral studies, 6(2014) 71-778 https://doi.org/10.4102/sajesbm.v11i1.165 